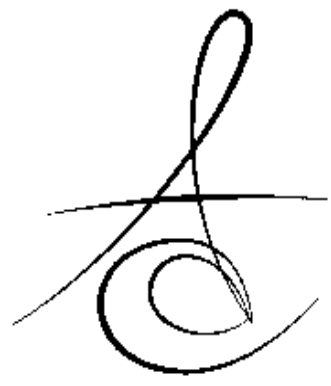

\title{
DİŞ HEKİMLİĞİNDE KULLANILAN CAD/CAM (BİLGİSAYAR DESTEKLİ TASARIM/BİLGİSAYAR DESTEKLİ ÜRETİM) SİSTEMLERİ VE MATERYALLER
}

\author{
DENTAL CAD/CAM (COMPUTER AIDED DESIGN/COMPUTER AIDED \\ MANUFACTURING) SYSTEMS AND MATERIALS
}

\author{
Arş. Grv. Dt. Merve TOKGÖZ ÇETİNDAĞ*
}

Doç. Dr. Ayşe MEŞE*

Makale Kodu/Article code: 2663

Makale Gönderilme tarihi: 11.03 .2016

Kabul Tarihi: 07.04.2016

\section{ÖZET}

CAD/CAM sistemleri (bilgisayar destekli tasarım/ bilgisayar destekli üretim) diş hekimliğinde 1985 yllından beri kullanılmaktadır. Son 30 yılda teknolojinin ilerlemesiyle üstün özelliklerde çeşitli klinik ve laboratuvar CAD/CAM sistemleri geliştirilmeye devam etmektedir. Özellikle hasta başında kullanılan CAD/CAM sistemlerinin yaygınlaşması ile birlikte protetik tedavilerin tek seansta bitirilmesi amaçlanarak, laboratuvar aşamalarının elimine edilmesini sağlayacak materyallerin gelişimi hızlanmıştır. Bu derlemede günümüzde diş hekimliğinde kullanılan CAD/CAM sistemleri ve materyaller anlatılmıştır.

Anahtar kelimeler: CAD/CAM, materyaller, sistemler

CAD/CAM (bilgisayar destekli tasarım/bilgisayar destekli üretim) tekniği optik tarayıcılar aracilı̆ıyla toplanan verilerin bilgisayar yazılımları kullanılarak üç boyutlu tasarımlara dönüştürülmesi esasına dayanır. Sistemdeki veri toplama ünitesi ile bazı sistemlerde direkt ağız içinden bazılarında ise model üzerinden, prepare edilen dişlere ait bilgiler taranır ve dijitalize veriler bilgisayara aktarılır. Bu şekilde üç boyutlu tasarımlar oluşturulur. Daha sonra bu tasarımlar sisteme bağlı aletlere aktarılarak feldspatik veya dökülebilir seramikten çeşitli üreticiler tarafından hazırlanmış porselen blokların freze edilmesi yolu ile istenilen restorasyonlar elde edilir. Freze işlemini takiben oklüzal uyumlama, cilalama işlemleri ve simantasyon yapilır.

Diş hekimliğinde CAD/CAM sistemleri ilk olarak 1980 'de Duret ve Preston tarafından kullanılmıştır. 1985 'de Moermann ve Brandestini'nin çalışmalarıyla

\section{ABSTRACT}

CAD/CAM systems (computer aided design/computer aided manufacturing) has been used in dentistry since 1985. In the past 30 years, development of various high quality chairside and laboratory CAD/CAM systems has been continued with the progress of technology. Especially the improvements of CAD/CAM systems lets the practitioners choose different restorative materials than the conventional ones, place chairside restorations and also descrease the laboratory procedures. This article describes currently used CAD/CAM systems and materials.

Key words: CAD/CAM, materials, systems

CEREC sistemi geliştirilmiştir. Bu sistemde, hazırlanmış olan kavitenin hasta başında direkt olarak ağız içi kamera ile digital olarak taraması yapılmış, restorasyon tasarımını takiben klinikte bulunan cihazda seramik bloktan inley üretilmiştir. Bu sistemle tek seansta restorasyon yapılması mümkün olduğu için gerçek bir yenilik kabul edilmiştir. ${ }^{1}$

Günümüzde CAD/CAM sistemleri inley, onley, laminate veneer, bölümlü kron, tam kron ve köprü sistemleri ${ }^{2-6}$, hareketli bölümlü protezlerin iskelet yapıları ${ }^{7}$, implant cerrahisinde kullanilan stentlerin tasarlanıp üretilmesi ${ }^{8}$ gibi geniş bir endikasyon alanını kapsamaktadır. Bu sistemler ayrıca maksillofasiyal protezlerin hazırlanmasında, implant destekli protezlerde dayanak olarak, kron-köprü ve hibrit protez alt yapı tasarımı ve üretiminde de kullanılmaktadır. ${ }^{9-15}$

Sistem temel olarak 3 yapı içerir.

-Preparasyonun intraoral veya ekstraoral olarak taranıp verilerin toplanması

\footnotetext{
* Dicle Üniversitesi Diş Hekimliği Fakültesi, Protetik Diş Tedavisi AD
} 
-Restorasyonun bilgisayarda 3 boyutlu olarak planlanması ve tasarımı (CAD),

-Sanal olarak hazırlanmış restorasyonun üretiminin gerçekleştirilmesi (CAM). ${ }^{1}$

Verilerin toplanarak kaydedilmesi aşaması değişik CAD/CAM sistemlerine göre farklılıklar göstermektedir. Verilerin toplanması mekanik ve optik sayısallaştırıcılar kullanarak yapılır.Mekanik sayısallaştırıcı, tarayıcının diş ile göreceli olarak pozisyonunu koruyarak, prepare edilen diş yüzeyinin tamamının haritasını oluşturur. Bu tip sayısallaştırıcılar genellikle dişin silikon ölçüsü gibi negatif yüzeylerden veri elde etmek için kullanılır. Ancak, tarama sırasında marjinal bölgelerde deformasyon görülebileceğinden, ölçü alınarak model elde edildikten sonra mekanik sayısallaştırıcıların kullanımı önerilmektedir. ${ }^{9,16}$

Optik sayısallaştırıcılar genellikle harekete duyarlıdırlar. Bu nedenle intraoral optik tarayıcılar ile veri toplanırken, hastanın ufak bir hareketi hazırlanan restorasyonun uyumunu etkileyebilmektedir. Optik sayısallaştırıcılar hızlı ve yüksek çözünürlüğe sahip veriler elde edilmesine olanak sağlamaktadırlar. Ancak gölgelenme ekstraoral optik sayısallaştırıcıların dezavantajıdır. Yeni geliştirilen tarayıcılarda modelin pozisyonu 3-5 farklı aks üzerinde değiştirilerek istenilen bölgenin tam olarak taranması sağlanabilmektedir. ${ }^{17}$

Bilgisayar ortamına kaydedilen veriler daha sonra bilgisayar yazılımı sayesinde noktacıklardan oluşan sanal modele dönüştürülmektedir. ${ }^{18}$ Restorasyonun tasarımı tamamlandıktan sonra CAD yazılımı, sanal modeli CAM ünitesini kontrol eden komutlar dizisine çevirmektedir.

CAD/CAM sistemlerinin ilk yıllarında restorasyonlar yalnızca prefabrik bloklardan frez veya elmas diskler kullanılarak freze edilip üretilmiştir. Eksiltme yöntemi olarak adlandırılan bu teknikte istenilen şekle ulaşmak için blok materyalden eksiltme yapılmaktadır.Bu yöntem etkin olsa da, tipik bir dental restorasyon elde edebilmek için prefabrik blokların \%90' uzaklaştırılmakta ve dolayısıyla boşa gitmektedir.

Eksiltme yöntemine alternatif olarak günümüzde ekleme yoluyla üretim sistemleri de bulunmaktadır. Seçici lazer sinterizasyonu, seramik veya metal restorasyonların üretimi için kullanılan ekleme yöntemlerinden birisidir. Bu yöntemde, restorasyonun bilgisayar tasarımında, mevcut CAD/CAM sistemlerindeki kesme işlemine benzer bir işlem dizisi kullanılmaktadır. Ancak

kesme işlemi yerine işlem dizisi sırasında, seramik veya metal toz havuzundaki materyal sürekli ilavelerle sinterize edilerek restorasyon tamamlanmaktadır. Böylece boşa harcanan, artık materyal kalmamaktadır. ${ }^{19}$

\section{CAD/CAM SİSTEMLERİNİN AVANTAJLARI:}

CAD/CAM uygulamalarının kullanımı bir çok avantajı beraberinde getirmiştir. Bunlar;

○ $\quad$ Geleneksel ölçü alma yöntemleri ortadan kalkmıştır. ${ }^{20,21}$

- Daha uyumlu restoratif materyallerin daha kısa süre içinde elde edilmeleri sağlanmıştır.

- $\mathrm{Bu}$ sistemlerle birlikte hata potansiyeli oldukça azalmıştır ve indirekt restorasyonlardan kaynaklanabilecek muhtemel çapraz kontaminasyonların önüne geçilmiştir. ${ }^{1}$

- Tek seansta uygulamalar yapılabildiği için hem hastalar hem de hekimler açısından zaman kaybı engellenmiştir. Bu sayede çeşitli klinik problemlere yol açabilecek ölçü almanın yanı sıra, geçici kron hazırlama gibi zorunluluklar da ortadan kalkmıştır.(CEREC ve E4D DENTIST SİSTEM) ${ }^{22}$

CAD/CAM DEZAVANTAJLARI

○
SİSTEMLERİNINN

restorasyonların

kullanımını kısıtlayan faktörlerin başında üretim maliyeti gelmektedir. Birçok yeni sistem geliştirilmesine rağmen CAD/CAM uygulamaları henüz ekonomik değildir.

ideal estetik beklentilerin her zaman karşılanamamasına neden olmaktadır. Ancak farklı renklerde blokların yavaş yavaş geliştirilmesi ile bu sorunda aşılmaya başlanmıştır.

- Derin subgingival marjinlere sahip dişlerin bilgisayar ortamına aktarılması da sorun olabilmekte, bu nedenle geleneksel sabit protez yapımında olduğu gibi iyi bir dişeti retraksiyonu yapmak zorunlu hale gelmektedir. ${ }^{23}$

Üretim metodlarına göre Dental CAD/CAM sistemleri; ${ }^{24}$

1. Direkt klinikte kullanılan sistemler; intraoral olarak diş preparasyonunu tarar ve restorasyon klinikte hazırlanır. Bu grupta kullanılan sistemler CEREC ve E4D Dentist sistemleridir.

2. Laboratuvarda kullanılan sistemler; alçı modelden veya ölçüden tarama yapılmaktadır. Bu

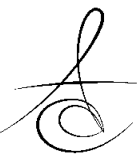


sistemlerin çoğunda altyapı üretilir ve teknisyen restorasyonu karakterize edebilmek için üzerine porselen ekler. CEREC inLab, DCS Preci-fit, Cercon, Everest sistemleri bu gruptadır.

3. Üretim merkezli CAD/CAM sisteminde ise, model laboratuvarda tarandıktan sonra veriler internetten ana üretim merkezine gönderilir. AltyapıSı hazırlanan restorasyon, üzerine porselen eklenmesi için laboratuvara geri gönderilir. Tüm altyapıların aynı merkezde yapılmasıyla optimal kalite kontrolü sağlanır. Procera ve Lava sistemleri bu şekilde çalışmaktadır.

\section{SİSTEMLERİ}

\section{1)KLINİKTE KULLANILAN CAD/CAM}

\section{A) CEREC}

CEREC ilk olarak 1985 yllında kullanılmaya başlanmıştır. 1994 ylında CEREC 2, 2000 yllında CEREC 3 piyasaya sürülmüştür. İlk CEREC sisteminin dezavantajları restorasyonların zayıf marjinal uyumları ve okluzal yüzeyin şekillendirilmesinde görülen başarısızlıklardı. ${ }^{25}$ CEREC 2 sistemi ile beraber bu problemler aşılmış ve CEREC 3 sistem ile yüksek başarı oranıyla restorasyonları elde etmek mümkün olmuştur.

CEREC Sistemlerinin Üretim İşlemleri: ${ }^{26}$

1-Diş preparasyonu tipik olarak tam seramik restorasyonların hazırlandığı gibi hazırlanır.

2-Opak bir toz (titanyum oksit/silistyum oksit) ile prepare edilen diş kaplanır.

3-Optik tarayıcı ile prepare edilen dişin bilgisayar monitörüne görüntüsü yansıtılır. Görüntü yakalanınca bilgisayara kaydedilir. belirlenir.

4-Bilgisayar ekranında marjinler ve konturlar

5-Uygun boyutta seçilen seramik blok şekillendirme ünitesine yerleştirilir. Bir kronun hazırlanma süresi yaklaşık 20 dakikadır.

6-Elde edilen restorasyonun ağızda kontrolü yapılır ve simante edilir.

Ağız içinde prepare edilmiş dişlerin optik olarak taranması aşamasında iki ayrı yöntem geliştirilmiştir. CEREC 3D, ağız içi kameranın ağızda sabit tutulup ayak pedalı yardımıyla görüntünün yakalanmasını sağlarken, CEREC AC ile bu işlem daha da geliştirilerek kamera ağızda sabit olarak tutulduğunda sistemin otomatik olarak görüntüyü yakalaması sağlanmıştır.

CEREC sisteminin biogeneric özelliği sayesinde hastanın mevcut dişlerine benzer morfolojide restorasyonlar üretilebilmektedir. Bu şekilde her bireye özel, kendi dişlerine benzer restorasyon yapılabilmektedir. CEREC sisteminde hekim bilgisayar tasarımı üzerinde istediği değişiklikleri yapar; karşıt dişle olan kontakt noktalarını kontrol edebilir, sanal olarak aşındırma, ekleme, kontür değişikliği yapabilir, komşu dişlerle kontakt noktalarının sıkılığını arttııp azaltabilir.

CEREC sistemiyle kullanılabilen materyaller feldspatik ve lösitle güçlendirilmiş cam seramikler olduğu gibi, lityum disilikat gibi yüksek dirence sahip seramikler, titanyum içerikli metal bloklar, nanoseramikler ve geçici amaçla kullanılan akrilik bloklarda olabilmektedir.

\section{B) EVOLUTION 4D DENTIST}

2005 yllında piyasaya sürülen E4D Dentist sistemi, yansıtıc toz olmadan intra-oral lazer tarayıc (Intraoral Digitizer) ile prepare edilen dişi tarayabilmektedir. Hekim birçok açıdan görüntü alarak veri noktalarını arttıır, böylece yazılım doğru morfolofiyi bilgisayarda oluşturabilir. Sahip olduğu IC Everything View parçası ile 3 boyutlu görüntülerde, yumuşak ve sert dokunun ayırt edilmesi, kronların çevresi ve ağız içi ortamının netliği görülmektedir.

Aynı anda 16 üyeye kadar restorasyon tasarımı yapılabilen DentaLogic yazılımına sahip olan cihazın "autogenesis" özelliğiyle anatomik yapılara uyumlu kişisel tasarım yapılabilmektedir. Üretici firmanın online ücretsiz yazılım güncellemesi yapması bu sisteme ilave avantaj sağlamaktadır.

Ancak kullanılabilecek malzeme çeşitliliğinin CEREC 3 kadar fazla olmaması sistemin dezavantajı olarak göze çarpmaktadır. Lösitle güçlendirilmiş seramik bloklar, titanyum içerikli metal bloklar, lityum disilikat bloklar, nanoseramik ve geçici amaçla kullanılan akrilik bloklar E4D Dentist sistemi ile uyumludur. ${ }^{27}$

\section{2) LABORATUVARDA CAD/CAM SİSTEMLERİ}

A) CEREC INLAB

Cerec Inlab sistemi 2004 yllında laboratuvar kullanımı için üretilmiştir. Bu sistemde lazer tarayıcı (inEos Blue) ile çalışma modelinin dijital görüntüsü alınır. Sistemin inEos Blue kısmı; tarayıcı, inLab 3D tarayıcı-tasarım yazılımı ve bilgisayar parçalarını içermektedir. InEos Blue kısmının dışında frezeleme ve sinterleme cihazı da sistemde bulunmaktadır.

Tasarım yazilımında bulunan patentli "biogeneric" özelliği ile hastanın mevcut dişlerine benzer morfolojide restorasyonlar yapılabilmektedir. Tasarım

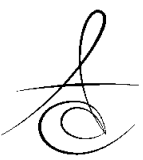


bittikten sonra inLab frezeleme cihaziyla restorasyon hazırlanır. Bu cihaz \pm 25 mikron hassasiyetle çalışmakta ve 10 üyeye kadar köprü frezeleyebilmektedir. Günde 40-60 üye restorasyon yapılabilir. Sinterleme fırını ile 5 üye köprü 90 dakikada sinterlenebilmektedir.

CEREC inLab sisteminin diğer bir özelliği de zirkonya köprü altyapılarıla beraber üzerine kulanılacak porseleni de freze ederek, daha sonra bu iki parçanın birbiriyle birleştirilmesine olanak sağlamasıdır. Bu şekilde elle yapılan porselen yığımı yerine, altyapıyla tam uyumlu ve oklüzal morfolojisi cihazın CAD kısmıyla önceden belirlenmiş olan üst yapı hazırlanır.

\section{B) DCS PRECI-FIT}

DCS Preci-fit sistem, 1990 ylında kullanılmaya başlanılmışıı. Cam seramik,güçlendirilmiş seramik ve metalleri freze etmesinin yanısıra, restorasyon altyapılarını tam sinterlenmiş bloklardan (DC-Zirkon) ve titanyumdan da (DCTitan) hazırlayabilen CAD/CAM sisteminden bir tanesidir. ${ }^{25}$

Sistem, Preciscan lazer tarayıcı ve Precimill frezeleme makinesini içermektedir. DCS Dentform yazıIımı köprülerde gövde şekillerini ve konnektör boyutlarını otomatik olarak belirlemektedir.

\section{C) CERCON}

Dentsply firmasına ait olan, 2002 yılında piyasaya sürüldüğünde sadece CAM sistemi olarak çalsşan sistem, 2005 yilında sisteme 3 boyutlu optik tarayıcı (Cercon eye) ve CAD tasarım yazilımı (Cercon Art) eklendikten sonra tam bir CAD/CAM sistemi halini almışır. Her bir üye 20 saniyeden kısa sürede, 10 mikron hassasiyetle taranabilmektedir.

Kron kenarları otomatik olarak belirlenmekte ve Cercon brain expert ile frezeleme, Cercon heat plus ile sinterleme yapılmaktadır. Sistem tek üyeden 9 üyeye kadar yarı sinterlenmiş zirkonya blokları freze edebilmekte ve 16 üyeye kadar köprü sinterlemesi yapabilmektedir.

\section{D) EVEREST}

Everest sistemi Kavo firması tarafından üretilmektedir. Sistem; tarayıcı (Everest Scan), aşındırma ünitesi (Everest Engine), sinterleme firını (Everest Therm) ve bu üniteler arası koordinasyonu sağlayan, tasarımın yapıılı̆ı̆ı bilgisayardan oluşur. Tarayıcı ile alçı model birlikte dönen tablaya yerleştirilir ve CCD (charge coupled device) kamerayla taranır. Taranan modelin 3 boyutlu dijital hali bilgisayarda oluşturulur. Tek üye kron restorasyonun tasarlanması 5 dakikada tamamlanabilir. Tasarımı takiben frezelemeye geçilir. Aşındırma ünitesinin 5 eksende frezeleme özelliği bulunmaktadır. Everest sistemiyle inley, onley, anterior ve posterior kron-köprü yapılabilmektedir.

\section{3.ÜRETİM MERKEZLI CAD/CAM SİSTEMLERİ \\ A)PROCERA}

Nobel Biocare tarafindan 1994 yilında piyasaya sürülmüş olup üretici firmanın verdiği bilgilere göre bu sistemle bugüne kadar 11 milyonun üzerinde restorasyon üretilmiştir.

Alumina ile yüksek hassasiyette kron altyapıları, veneer ve abutmentlar yapılabildiği gibi, zirkonyadan da abutment ve kron-köprü altyapısı yapılabilmektedir. Öncelikle modelin 20.000 ölçüm noktası veren taraması yapilır. Laboratuvara kurulan kompakt bir tarama cihazıyla alçı modelin taraması bittikten sonra elde edilen veriler internet yardımıyla $A B D$ veya İsveç'te bulunan üretim merkezine gönderilir. ${ }^{28}$ Üretim merkezinde seramiğin büzülmesini kompanze edebilecek büyüklükte genişletilmiş (\%30 oranında) day'lar hazırlanır. Genişletilmiş day üzerinde hazırlanmış ve sinterlenmiş altyapılar üzerine, porselen uygulaması yapılır ve bitim için altyapılar tekrar teknisyene gönderilir. ${ }^{29}$

Procera AllCeram sisteminde yoğun olarak sinterlenmiş, saf ve yüksek dayanıklılıkta alüminyum oksit (\%99.5) altyapılar üretilmektedir. ${ }^{30}$ Ayrıca zirkonyumoksit altyapılı restorasyonlar (Procera AllZirkon), titanyum altyapılı restorasyonlar (Procera AllTitan), titanyum veya alüminyum oksit abutmentlar, implant üstü tam seramik kronlar ve implant üstü titanyum köprü altyapılarının üretimi de Procera sistemi ile mümkündür. ${ }^{31}$

\section{B) LAVA}

Lava sistemi 2002 yılında 3M ESPE tarafından piyasaya sürülmüştür. Sistemde optik tarayıcı ( Lava Scan ST), frezeleme makineleri (Lava CNC 240 veya 500) ve sinterleme firını (Lava Furnace 200) bulunmaktadır. Kron-köprü altyapıları üretim merkezlerinde hazırlanır. Lava sistemi otomatik olarak kron kenarlarını ve gövdenin oturacağı yeri belirler. Yapılacak altyapı sinterleme büzülmesini kompanze edebilmek için \%20-25 oranında büyük tasarlanır.

Pre-sintered yani yarı sinterlenmiş zirkonya bloklar kullanılır. Tasarım sonrasında restorasyon uygun boyuttaki bloklardan freze edilir. Her blokta barkod numarası bulunur ve uygun bloğun barkodu okunduktan sonra frezelemeye başlanır. Tek üye 
altyapı 15 dakika, 3 üye köprünün frezelenmesi yaklaşık 45-50 dakika sürmektedir. Sinterleme öncesi 7 farklı seçenekte renklendirme yapılabilir. Bu işlem frezeleme sonrasında restorasyonun renklendirici solüsyona batırımasıyla yapılır. Böylece alt yapının üst yapı porseleni ile daha iyi uyum göstermesi ve estetiğin artması sağlanır.

Sinterlenen altyapılar, zirkonyanın ısısal genleşme katsayısı ile uyumlu olan Lava Ceram materyali ile bitirilir. ${ }^{32}$ Lava Ceram dışında uyumlu porselen tozlarıyla da üst yapı hazırlanabilmektedir. Optik ve mekanik özelliklerinden dolayı hem anterior hem de posteriorda kullanılabilir.

CAD/CAM sistemlerinin kullanımlarının yaygınlaşması ile estetik ve fonksiyonel beklentiler artmıştır. Beklentinin artmasıyla birlikte farklı birleşimlere, yapısal ve fiziksel özelliklere sahip materyaller geliştirilmiştir. Üretimde kullanılan blok materyalleri restorasyon tipine, restorasyonun ağızdaki konumuna, hastanın beklentilerine, sosyo-ekonomik durumuna ve hekimin tercihine göre değişkenlik göstermektedir. dir; $; 3,34$

$\mathrm{Bu}$ materyaller şu şekilde sınıflandırılmakta-

1. Feldspatik seramikler

2. Lösitle güçlendirilmiş cam seramikler

3. Lityum disilikatla güçlendirilmiş cam seramikler

4. Oksit seramikler

5. Cam infiltre oksit seramikler

6. Sinterlenen oksit seramikler

7. Nanoseramikler

8. Hibrit seramikler

9. Zirkonya ile güçlendirilmiş lityum disilikat seramikler

10. Kompozitler

11. Polimerler

12. Metaller

\section{FELDSPATİK SERAMİKLER}

Feldspatik seramik içerikli bloklar diş hekimliğinde CAD/CAM sistemlerinde kullanılan ilk bloklardır. Bu bloklarla yapılan 10 yıllık bir çalışmada, \%90.4 gibi oldukça yüksek bir başarı elde edildiği görülmüştür. ${ }^{35}$

Cam matriks içerisinde \%30 oranında ve homojen dağılmış 3-4 mikrometre boyutlarında feldspar partikülleri bulunmaktadır. Kırılma dirençleri 150 Mpa, elastiklik modülleri 45-63 Gpa'dır. ${ }^{34}$

Monokromatik, dikromatik ve polikromatik olarak 3 farklı feldspatik seramik blok mevcuttur. Monokromatik blokların geliştirilme çabaları dikromatik ve polikromatik blokların geliştirilmesini sağlamıştır. Dikromatik bloklarda küresel bir dentin çekirdeği ve etrafında translusent mine tabakası bulunmaktadır. Bu bloklarda renk geçişi dentin ve mineyi taklit etmek amacıyla 3 boyutlu olarak bir yay şeklinde hazırlanmıştır. Polikromatik bloklar farklı renk doygunluğu ve ışık geçirgenliklerine sahip olmaları nedeniyle doğal diş dokusunu taklit edebilmektedirler. Böylece doğal dişin optik özelliklerini kopyalayarak mevcut doğal dentisyon ile restorasyonun bir bütün oluşturması sağlanmaktadır. ${ }^{36}$

Bu bloklar inley, onlay, laminate veneer, parsiyel kron ve full kron yapımına uygundurlar. ${ }^{37}$ Cam içeriklerinin fazla olması nedeniyle hidroflorik asitle pürüzlendirilebilir ve adeziv simantasyonda oksit seramiklere oranla daha başarılı sonuçlar verirler. Mekanik olarak cilalanabilirlikleri oldukça iyidir. Bu bloklar tüm bu özellikleri sayesinde chairside (hasta başı tek seans uygulamaları) uygulamalarına oldukça uygundur. ${ }^{38,39}$

\section{LÖSİTLE GÜÇLENDİRİLMISŞ CAM SERAMİKLER}

Seramik içinde bulunan lösit kristalleri çok aşamalı fabrikasyon işlemleri ile cam matrikste kontrollü kristalizasyon oluşturularak üretilmektedir. Sistemde kullanılan lösit esasllı cam seramik materyal temel olarak silisyum oksit $\left(\mathrm{SiO}_{2}\right)$, alüminyum oksit $\left(\mathrm{Al}_{2} \mathrm{O}_{3}\right)$ ve potasyum oksitten $\left(\mathrm{K}_{2} \mathrm{O}\right)$ meydana gelmiştir. ${ }^{40}$ Silikat cam matriks hacminin \%30-40 kadarını 1-5 mikrometre büyüklüğündeki lösit kristal fazı oluşturur. ${ }^{41}$ Materyalin yarı geçirgenlik özelliği ve aşındırma etkisi doğal dişe benzerken, bükülmeye karşı direnci ise 160 Mpa'dır. ${ }^{42}$

Lösit kristallerinin materyalin direnci üzerindeki etkisi iki farklı mekanizma sonucunda ortaya çıkmaktadır. Bunlardan birincisi; lösit kristallerinin çatlağın yönünü değiştirerek çatlak ilerlemesini durdurmasıdır. ${ }^{43}$ Diğer mekanizma ise; seramiğin soğuması sırasında cam matriks içerisinde artık baskı geriliminin oluşmasıdır. Yapı içerisinde \%40 oranında bulunan lösit kristallerinin genleşme katsayısı, içinde bulunduğu cam matriksten daha fazladır. Seramik ısıtılıp soğutulurken lösit kristalleri büzülerek, cam matriksi kendine doğru çeker ve böylece yapı içinde oluşan iç basınç mikro çatlakların ilerlemesini durdurur. ${ }^{44}$

$\mathrm{Bu}$ materyallerin renk, translusentlik, floresanslık, opalesanslık, aşınma ve abrazyona direnç gibi özellikleri doğal dişe benzerlik göstermektedir. Restorasyonların direnci, diş dokusuna olan başarılı adez-

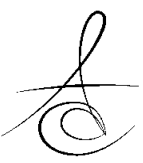


Atatürk Üniv. Diş Hek. Fak. Derg.

J Dent Fac Atatürk Uni

Cilt:26, Sayı: 3, Yıl: 2016, Sayfa: 524-533

yona bağlıdır ve adeziv simantasyon gerektirmektedir. Endikasyonları anterior bölge kron ve laminate veneer ile sınırlıdır. ${ }^{45}$

\section{LİTYUM DİSİLİKATLA GÜÇLENDİRİLMİş CAM SERAMİKLER}

Cam seramik restorasyonların endikasyonlarının genişletilmesi amacıyla daha yüksek dayanım ve kırılma direncine sahip materyallerin geliştirilmesine ihtiyaç duyulmuştur. Bu sistemde alt yapı seramiğini güçlendirmek amacıyla lösit cam seramiklere kıyasla çok daha yüksek miktarda kristal içeriği bulunmaktadır. Materyalde \%70 oranında lityum disilikat kristalleri kullanılmaktadır, üst yapı seramiği ise florapatit kristallerinden oluşmaktadır. ${ }^{46,47}$

Lityum disilikat materyalinin freze edilmesinin çok zor olması ve de aynı zamanda materyalin kırılganlığından dolayı CAD/CAM sistemlerinde kullanılmak üzere hazırlanan blokların üretim aşamasında farklı prosedürler gerekmektedir. CAD/CAM sistemleri ile kullanılan lityum disilikatla güçlendirilmiş cam seramiklerin üretim sürecinde seramik, parsiyel olarak kristelize edilmektedir. Parsiyel kristelizasyonun amacı blokların hem kolay ve hızlı bir şekilde freze edilmesini sağlamak, hem de frezeleme işlemi sırasında seramiğe yeterli direnci kazandırmaktır. Parsiyel kristalize bloklardaki temel kristal faz lityum metasilikattır $\left(\mathrm{Li}_{2} \mathrm{Si}_{2} \mathrm{O}_{3}\right)$. $\mathrm{Bu}$ özellikteki materyal oldukça düşük kimyasal ve mekanik dayanıma sahiptir. $850^{\circ} \mathrm{C}$ 'de uygulanan kristalizasyon işlemi sonrasında lityum metasilikat dirençli ve diş rengindeki lityum disilikata dönüşür. ${ }^{48}$

Üç farklı ışık geçirgenliğine sahip lityum disilikat CAD blokları mevcuttur. Yüksek translusensiye sahip bloklar, çevre dokuların rengini absorbe etme özelliğine (bukalemun efekti) sahip olması ve estetik özellikleriyle, inlay ve onlay restorasyonların yapımında kullanılabilmektedir. Düşük translusensiliğe sahip bloklar ise çeşitli renk seçenekleri ile full anatomik restorasyonların yapımında kullanılabilmektedir. Renkleşmiş dişlerin tedavisinde, tabakalama tekniğiyle multi blokların kullanımı uygundur. Daha estetik bölgelerde cut-back tekniği ile üst yapı porseleni uygulanabilir. ${ }^{49}$

Üretici firmaların önerileri doğrultusunda 0.8 $\mathrm{mm}$ kalınlıkta hazırlanan altyapı sayesinde kırılma direnci 400 40 Mpa'a kadar arttırılmıştır. Bu sayede tek kron restorasyonlarının yanı sıra, 3 üyeli köprü protezlerinin yapımı da mümkün olup endikasyon alanı 2.premolar dişlerinin anterior bölgesi ile sınırlıdır. ${ }^{50}$

\section{OKSİT SERAMİKLER \\ A.CAM İNFİLTRE OKSİT SERAMİKLER}

$\mathrm{Bu}$ seramik sistemleri son sertliklerine ulaşabilmeleri için lanthan oksit cam infiltrasyonu işlemine maruz kalırlar. Bu bloklar In-Ceram Spinell, In-Ceram Alumina ve In-Ceram Zirconia olmak üzere 3'e ayrilır.

In-Ceram Spinell 1994 yılında opak altyapıya sahip In-Ceram Alumina materyaline estetik açıdan daha başarılı bir alternatif olarak üretilmiştir. In-Ceram materyalleri arasında en fazla translusensliğe sahip olan materyaldir. Bükülme direnci In-Ceram Alumina materyaline göre $\% 25$ daha düşüktür. ${ }^{51}$ Translusensliği ise 2 kat daha fazladır. Translusens özelliği sayesinde estetik beklentinin fazla olduğu anterior bölge restorasyonlarında tercih edilir. ${ }^{52}$

In-Ceram Alumina 1989 yılında yüksek oranda sinterlenmiş pöröz alumina altyapı materyaline, düşük viskoziteli sodyum lanthan oksit cam infiltrasyonuyla elde edilmiştir. Anterior, posterior bölge kronlarda ve üç üyeli anterior bölge köprülerde altyapı materyali olarak kullanılır. ${ }^{53}$

In-Ceram Zirconia alüminyum oksit içeriğine ilave olarak \%33 oranında seryum stabilize zirkonyum katılarak piyasaya sürülmüştür. In-Ceram Zirconia $1100^{\circ} \mathrm{C}$ 'de iki saat süreyle sinterlendikten sonra cam infiltrasyonu gerçekleşmektedir. Cam faz son halini almış yapının yaklaşık \%23 'ünü oluşturmaktadır. ${ }^{54,55}$

\section{B.SİNTERLENEN OKSİT SERAMİKLER -ALÜMİNYUM OKSİT}

Bu seramikler presinterize durumdadır ve restorasyon üretildikten sonra $1520^{\circ} \mathrm{C}$ de fırınlanırlar. $\% 100$ alüminyum oksit kristalleri içeren yarı sinterlenmiş, yüksek dayanıklılı̆a sahip oksit bloklardır. Kırılma dayanımı 500 MPa'ın üzerinde olup, bükülme dayanımı ortalama $610 \mathrm{MPa}$, elastik modülü ise $380 \mathrm{GPa}$ dır. Frezelenme işlemi sonrasında cam infiltrasyonu gerektirmez. Bu bloklar tek renklidirler; fakat daha sonra üzerine yığılacak porselen rengine göre renklendirme likitiyle renklendirilebilirler. ${ }^{55}$

\section{-ZİRKONYUM OKSİT}

Yüksek mekanik direnci, kimyasal ve boyutsal stabilitesi ile ön plana çıkan zirkonyum günümüzde, tam porselen restorasyonların alt yapılarının yapımında en çok kullanılan materyaldir. ${ }^{56}$ Üretim şekillerine göre zirkonyum dioksit bloklar 3 grupta incelenirler.

Sinterlenmemiş zirkonyum dioksit bloklar, üretim aşamasında zirkonyum dioksit tozunun herhangi bir sinterleme işlemi uygulanmadan basınçsız bir

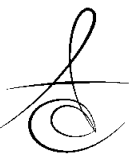


şekilde preslenmesi ile üretilir. Kolay aşındırıı sonrasında sinterlenerek kullanılırlar. ${ }^{57}$

Yarı sinterlenmiş zirkonyum dioksit bloklar, zirkonyum dioksit tozunun yapı içerisine bağlayıcı madde konularak preslenip blok haline getirilmesi ile üretilirler. Zirkonyum dioksit tozu, üretici firma tarafından ISı uygulamadan basınçla sıkıştırılır ve $1350-1550^{\circ} \mathrm{C}$ ISıda ön sinterleme işlemine tabi tutulur. ${ }^{37}$

Tam sinterlenmiş zirkonyum dioksit bloklar, ilk olarak $1300^{\circ} \mathrm{C}^{\prime}$ de sinterlenir ve $\% 95$ yoğunluğa ulaşır. Oluşan yapı çok sert olduğu için aşındırma işlemi uzun zaman almaktadır. ${ }^{57}$

\section{NANOSERAMİKLER}

Nanoseramikler, nanoboyutta seramik partikülleri ve UDMA (üretan dimetakrilat) içerikli reçine matriksten oluşmaktadır. Yapı içerisinde $20 \mathrm{~nm}$ çapında silika nanomerler ve 4-11 nm çapında zirkonya nanomerler bulunmaktadır. Blokların üretim aşamasında yapıya katılan silan, reçine matriks ve nanomer yapı arasında kimyasal bağlantı oluşumunu sağlamaktadır. $^{58}$

Materyalin \%80'i polimerik bir matriks içine gömülü birbirine bağlı $20 \mathrm{~nm}$ çapında silika, 4-11 nm çapında zirkonyum dioksit nano partikülleri içerir. Nanoseramik materyalinin elastik modülü $10-20 \mathrm{Gpa}$ olup, dentine yakın değerler gösterdiği ve cam seramiklere oranla stresi daha fazla absorbe ettiği belirtilmiştir. Kırılma direnci 204 MPa olup; feldspatik, lösit ve kompozit bloklardan yüksek, lityum disilikatla güçlendirilmiş bloklara yakındır. ${ }^{59}$ Nanoseramiklerin şok absorbe etme özelliklerinin olduğu ve implantüstü restorasyonlarda seramiklere nazaran daha başarılı sonuçlar verdiği belirtilmektedir. Ayrıca karşı dişte meydana getirdikleri aşınma, cam seramiklere oranla çok daha azdır. ${ }^{60}$

\section{HİBRİD SERAMİKLER}

$\mathrm{Bu}$ blokların yapısında baskın oranda bulunan seramik ağı, birbiri içerisine tamamen entegre olan bir polimer ağı ile güçlendirilmiştir. Bu sayede bu yapıdaki materyallerde seramik ve kompozit materyallerinin pozitif özellikleri bir araya toplanmıştır. Ağırlıkça \%86'sını, hacimce \%75'ini seramik yapı oluşturur. Polimer ağı, yüzeyi modifiye edilmiş polimetilmetakrilattan (PMMA) oluşmaktadır. Seramik materyalinde sık karşılaşılan çatlak ilerlemesi sorunu polimer ağ yapısı sayesinde azaltılmıştır. Yüksek yükleme kapasiteleri sayesinde özellikle posterior bölgede yapılacak kron restorasyonlarında kullanılırlar. ${ }^{60}$

\section{ZİRKONYA İLE GÜÇLENDİRİLMİŞ LİTYUM DİSİLİKAT SERAMİKLER}

Lityum disilikatla güçlendirilmiş cam seramikler, CAD/CAM sistemlerinde ilk kullanılan bloklardan birisidir. Bu bloklar günümüzde mekanik açıdan geliştirilerek, zirkonya infiltre lityum disilikat seramik bloklar üretilmiştir. Seramik yapı içerisinde \%56-64 $\mathrm{SiO}_{2}$, \%15-21 Li $2 \mathrm{O}, \% 1-4 \quad \mathrm{~K}_{2} \mathrm{O}, \% 3-8 \mathrm{P}_{2} \mathrm{O}_{5}, \% 1-4$ $\mathrm{Al}_{2} \mathrm{O}_{3}$ ve \%8-12 $\mathrm{ZrO}_{2}$ bulunmaktadır. Frezelemeden sonra kırılma direnci $210 \mathrm{MPa}$ iken kristalleşme sonrası kırılma direnci 420 MPa'a ulaşır. ${ }^{61}$

\section{KOMPOZITLER}

Yapısal, fiziksel, biyolojik ve estetik özelliklerinin sağladığı avantajlardan ötürü akrilik reçine esaslı bloklara oranla daha başarılı olan kompozit reçine esaslı bloklar kullanılarak, daha üstün estetik ve biyolojik özelliklere sahip uzun süreli geçici restorasyonlar hazırlanabilmektedir. Ayrıca özellikle bruksizim sorunu olan hastalarda, hem karşı dişte daha az aşınmaya neden olan, hem de çiğneme kuvvetlerini absorbe edebilen bu tür malzemeler kullanılarak tek diş kron restorasyonları ve inley onlay restorasyonları hazırlanması da mümkündür. ${ }^{62}$

\section{POLİMERLER}

Uzun süreli geçici restorasyonlar olarak kullanılır. Bazı durumlarda rezin materyalden restorasyonlar üretilip marjin adaptasyonundan veya estetik görüntüsünden emin olunup daha sonra maliyeti çok daha yüksek seramik bloklardan üretime geçilmektedir. Bu amaçla kullanılan monokromatik ve daha üstün optik özelliklere sahip polikromatik bloklar bulunduğu gibi, üretici firmalar tarafından içeriğinde polimetilmetakrilat bulunmayan mateyallerde piyasaya sürülmüştür. Bunun yanında akrilik reçine esaslı blokların CAD/CAM sistemlerinde kullanımıyla artık monomer bırakmadan döküme girebilen altyapı modelajları ve cerrahi plaklarda hazırlanabilmektedir. ${ }^{63}$

\section{METALLER}

Diş hekimliğinde yaygın olarak saf titanyum, titanyum alaşımları ve krom-kobalt alaşımları kullanılmaktadır. CAD/CAM sistemlerinin gelişimiyle birlikte, özellikle implantüstü restorasyonlarda bar yapımı esnasında ya da metal destekli seramik restorasyonlar üretirken dökümden kaynaklanan büzülmeleri ve uyumsuzlukları engellemek ve pasif uyumu sağlamak amacıyla bu materyallerden üretilmiş bloklar kullanılır. ${ }^{64}$

Geçmişten beri kullanılan geleneksel metal blokların yanı sıra güncel bir materyal olan sinterlenen 
metal bloklarda son zamanlarda piyasada yerini almışıır. Bu bloklardan restorasyonların üretilmesi, zirkonya esaslı bloklardan restorasyon üretim süreci ile benzerlik göstermektedir. Kısmi sinterlenmiş metal bloklar, sinterlendikten sonra gösterdikleri büzülme miktarı göz önünde bulundurularak $\% 110$ oranında daha büyük freze edilirler. Freze edilen restorasyonlar argon gazlı ortamda sinterlenerek mekanik özellikler ve boyut bakımından son haline ulaşır. ${ }^{65}$

\section{SONUÇ VE YORUM}

Sahip oldukları geniş ürün yelpazesiyle diş hekimliğinde yaygın kullanım alanı bulan CAD/CAM sistemleri güncel yaklaşımlardır. Konvansiyonel teknikler ve materyallerle hazirlanan restorasyonlarla karşılaştıııldığında teknik anlamda avantajlar getirse de CAD/CAM ve kullanılan materyallerle ile ilgili daha çok bilimsel çalışma yapılması gerekmektedir.

\section{KAYNAKLAR}

1. Karaalioğlu OF , Duymuş ZY , Diş hekimliğinde uygulanan CAD /CAM sistemleri , Atatürk Üniv Diş Hek Fak Derg. 2008; 18: 25-32.

2. Strub JR, Rekow ED, Witkowski S, Computer-aided design and fabrication of dental restorations: Current systems and future possibilities, J Am Dent Assoc. 2006; 137: 1289- 96.

3. Giordano R, Materials for chairside CAD/CAMproduced restorations, J Am Dent Assoc. 2006; 137: 14-21.

4. Fasbinder DJ, Clinical performance of chairside CAD/CAM restorations, J Am Dent Assoc. 2006; 137: 225-315.

5. Raigrodski $\mathrm{AJ}$, Contemporary materials and technologies for all-ceramic fixed partial dentures: a review of the literatüre, J Prosthet Dent. 2004 Dec; 92: 557-62.

6. Sjögren G, Molin M, van Dijken JWV, A 10-year prospective evaluation of CAD/CAM-manufactured (Cerec) ceramic inlays cemented with a chemically cured or dual-cured resin composite, Int J Prosthodont. 2004; 17: 241-6.

7. Denissen HW, van der Zel JM, van Waas MAJ, Measurement of the margins of partial-coverage tooth preparations for CAD/CAM, Int J Prosthodont. 1999; 12: 395-400.
8. Williams RJ, Bibb R, Rafik $T, A$ technique for fabricating patterns for removable partial denture frameworks using digitized casts and electronic surveying, J Prosthet Dent. 2004; 91: 85-8.

9. Marchack $C B, C A D / C A M$-guided implant surgery and fabrication of an immediately loaded prosthesis for a partially edentulous patient, J Prosthet Dent. 2007; 97: 389- 94.

10. Williams RJ, Bibb R, Eggbeer $D$, Collis J, Use of CAD/ CAM technology to fabricate a removable partial denture framework, J Prosthet Dent. 2006; 96: 96-9.

11. Bibb R, Bocca A, Evans $P, A n$ appropriate approach to computer aided design and manufacture of cranioplasty plates, J Maxillofac Prosthet Technol. 2002; 5: 28-31.

12. Chen LH, Tsutsumi S, Iizuka T, A CAD/CAM technique for fabricating facial prosthesis: $A$ preliminary report, Int J Prosthodont. 1997; 10: 467-72.

13. Yüzügüllü $B, A v c l ~ M$, The Implant-Abutment Interface of Alumina and Zirconia Abutments, Clin Implant Dent Relat Res. 2008 Jan 24; [Epub ahead of print]

14. Drago $\mathrm{CJ}$, Peterson $\mathrm{T}$, Treatment of an edentulous patient with CAD/CAM technology: A clinical report, J Prosthodont. 2007; 16: 200-8.

15. Kupeyan HK, Shaffner M, Armstrong J, Definitive $\mathrm{CAD} / \mathrm{CAM}$-guided prosthesis for immediate loading of bone- grafted maxilla: A case report, Clin Implant Dent Relat Res. 2006; 8: 161-7.

16. Witkowski S, CAD-CAM in dental technology, Quintessence Dent Technol. 2005; 28: 169-184.

17. Ersu B, Yüzügüllü $B$, Canay $S$, Sabit Restorasyonlarda CAD-CAM Uygulamaları, Hacettepe Üniv Diş Hek Fak Derg. 2008; 32: 5872.

18. Sertgöz A, Balcı B, Diş Hekimliğinde CAD-CAM Teknikleri, Türk Diş Hekimleri Birliği Dergisi. 2007; 102: 61-7.

19. Baysal B, Diş hekimliğinde Bilgisayar Destekli Tasarım ve Üretim, Dentalife. 2007 Haziran; 18-22.

20. Palin W, Burke FJ, Trends in indirect dentistry: Cad/Cam Technology, Dent Update. 2005; 32: 566-72.

21. Duret $D$, Preston JD, CAD/CAM imaging in dentistry, Curr Opinion Dent. 1991; 1: 150-154.

22. Feuerstein $\mathrm{P}$, Can technology help dentists deliver

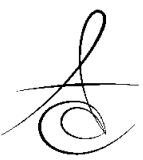


better patient care?, J Am Dent Assoc. 2004; 135; 11-6.

23. Christensen GJ, Computerized restorative dentistry: State of the art, J Am Dent Assoc. 2001; 132: 1301- 3

24. Giordano $R$, Materials for Chairside CAD/CAM produced restorations, J Am Dent Assoc. 2006; 137: 14-21.

25. Liu PR, Essig ME, A panorama of dental CAD/CAM restorative systems, Compend Contin Educ Dent. 2008; 29: 482-93.

26. Rosentiel SF, Land MF, Fujimoto J, Contemporary fixed prosthodontics, The C. V. Mosby Company. 2001: 643-72.

27. Çelik G, Computer aided dentstry and current CAD/CAM systems, Cumhuriyet Dent J. 2013; 16: 74-82.

28. Miyazaki T, Hotta $Y$, Kunii J, Kuriyama S, Tamaki $Y, A$ review of dental CAD/CAM: current status and future perspectives from 20 years of experience, Dent Mater J. 2009; 28: 44-56.

29. Andersson M, Ogden A, A new all- ceramic crown: a densely sintered, high purity alumina coping with porcelain, Acta Odontol Scand. 1993; 51: 59-64.

30. Conrad HJ, Seong WJ, Pesun IJ, Current ceramic materials and systems with clinical recommendations: a systematic review, J Prosthet Dent. 2007; 98: 389-404.

31. Ural Ç, Diş hekimliği pratiğinde tamamı seramik restorasyonlar ve Cad/Cam uygulamaları, Cumhuriyet Dent J. 2011; 86: 27-38.

32. Piwowarczyk A, Ottl P, Lauer HC, Kuretzky T, A clinical report and overview of scientific studies and clinical procedures conducted on the 3M ESPE Lava All-Ceramic System, J Prosthodont. 2005; 14: 39-45.

33. Fasbinder DJ, Materials for chairside CAD/CAM restorations, Compend Contin Educ Dent. 2010; 31: 702-704, 706-9.

34. Fasbinder DJ, Chairside CAD/CAM: an overview of restorative material options, Compend Contin Educ Dent. 2012; 33: 50, 52-8.

35. Otto T, de Nisko $S$, Computer-aided direct ceramic restorations: a 10-year prospective clinical study of Cerec CAD/CAM inlays and onlays, Int J Prosthodont. 2002; 15: 122-8.

36. Reich $\mathrm{S}$, Hornberger $\mathrm{H}$, The effect of multicolored machinable ceramics on the estetics of all-ceramic crowns, J Prosthet Dent. 2002; 88: 44-9.

37. Denry I, Kelly JR, State of the art of zirconia for dental applications, Dent Mater. 2008; 24: 299307.

38. Sorensen JA, Kang SK, Avera SP, Porcelaincomposite interface microleakage with various porcelain surface treatments, Dent Mater. 1991; 7: 118-23.

39. Sorensen JA, Munksgaard EC, Ceramic inlay movement during polymerization of resin luting cements, Eur J Oral Sci. 1995; 103: 186-189.

40. Pröbster L, Geis-Gerstorfer J, Kirchner E, Kanjantra $P$, In vitro evaluation of a glass-ceramic restorative material, J Oral Rehabil. 1997; 24: 636-645.

41. Kelly JR, Nishimura I, Campbell SD, Ceramics in dentistry: historical roots and current perspectives, J Prosthet Dent. 1996; 75: 18-32.

42. Giordano RA, Dental ceramic restorative systems, Compend Contin Educ Dent. 1996; 17: 779-82.

43. Albakry M, Guazzato M, Swain MV, Biaxial flexural strenghth and microstructure changes of two recycled pressable glass ceramics, J Prosthodont. 2004; 13: 141-9.

44. Tinschert J, Zwez D, Marx R, Anusavice KJ, Structural reliability of alümina-feldspar-leucitemica and zirconia-based ceramics, J Dent. 2000; 28: 529-35.

45. Fasbinder DJ, Restorative material options for CAD/CAM restorations, Compend Contin Educ Dent. 2002; 23: 911-916, 918-20.

46. Pagniano RP, Seghi RR, Rosenstiel SF, Wang R, Katsube $\mathrm{N}$, The affect of a layer of resin luting agent on the biaxial flexural strenght of two allceramic systems, J Prosthet Dent. 2005; 93: 45966.

47. Rosenstiel SF, Land MF, Fujımato J, Contemporary fixed prosthodontics, $4^{\text {th }}$ ed, St Louis: Mosby Elsevier;2006.

48. Ritzberger C, Apel E, Höland W, Perschke A, Rheinberger VM, Properties and clinical application of three types of dental glass-ceramics and ceramics for CAD/CAM Technologies, Metarials. 2010; 33: 700-13.

49. Guess PC, Zavanelli RA, Silva NR, Bonfante EA, Coelho PG, Thompson VP, Monolithic CAD/CAM lihium disilicate versus veneered YTZ-P crowns: comparison of failure modes and reliability after fatigue, Int J Prosthodont. 2010; 23: 434-42. 
50. Taskonak B, Mecholsky JJ Jr, Anusavice KJ, Residual stress in bilayer dental seramics, Biomaterials. 2005; 26: 3235-41.

51. Magne $P$, Belser $U$, Esthetic improvements and in vitro testing of In-Ceram Alumina and Spinell ceramic, Int J Prosthodont. 1997; 10: 459-466.

52. Fradeani M, Redemagni M, An 11-year clinical evaluation of leucite-reinforced glass-ceramic crowns: a retrospective study, Quintessence Int. 2002; 33: 503-10.

53. Sorensen JA, Torres $\mathrm{TJ}$, In Ceram ceramic bridge technology, Quint Dent Technol. 1992; 15: 41-46.

54. Deville S, Chevalier J, Fantozzi G, Bartolome JF, Requena J, Moya JS. Low-temperature ageing of zirconia toughened alumina ceramics and its implication in biomedical implants. J Eur Ceram Soc. 2003; 23: 2975-82.

55. Guazzato M, Albakry M, Ringer SP, Swain MV, Strenght, fracture toughness and microstructure of a selection of all-ceramic materials, Part II, Zirconia based dental ceramics, Dent Mater. 2004; 20: 449-56.

56. Conrad HJ, Seong WJ, Pesun IJ, Current ceramic materials and systems with clinical recommendations: a systematic review, J Prosthet Dent. 2007; 98: 389-404.

57. Beuer F, Schweiger J, Edelhoff D, Digital dentistry: an overview of recent developments for CAD/CAM generated restorations, Br Dent J. 2008; 204: 50511.

58. Fradeani M, D'Amelio M, Redemagni M, Corrado M, Five-year follow-up with Procera all-ceramic crowns, Quintessesence Int. 2005; 36: 105-113.

59. Zhang Y, Lee JJ, Srikanth R, Lawn BR, Edge chipping and flexural resistance of monolithic ceramics, Dent Mater. 2013; 29: 1201-8.

60. Raigrodski AJ, Contemporary all ceramic fixed partial dentures:a review, Dent Clin North Am. 2004; 48: 531-44.

61. Güth JF, Zuch T, Zwinge $S$, Engels J, Stimmelmayr $M$, Edelhoff $D$, Optical properties of manually and CAD/CAM-fabricated polymers, Dent Mater J. 2013; 32: 865-71.

62. Höland W, Schweiger M, Frank M, Rheinberger V, A comparison of the microstructure and properties of the IPS Empress glass ceramics, ] Biomed Mater Res. 2000; 53: 297-303.
63. Lauvahutanon S, Takahashi H, Shiozawa M, Iwasaki N, Asakawa $\mathrm{Y}$, Oki M, et al, Mechanical properties of composite resin blocks for CAD/CAM, Dent Mater J. 2014; 33: 705-10.

64. Mehl C, Harder S, Byrne A, Kern M, Prosthodontics in digital times: a case report, Quintessence Int. 2013; 44: 29-36.

65. Zimmermann $M$, Mehl A, Reich S, New CAD/CAM materials and blocks for chairside procedures, Int J Comp Dent. 2013; 16: 173-81.

\author{
Yazışma Adresi \\ Merve TOKGÖZ ÇETINDAĞ \\ Dicle Üniversitesi Diş Hekimliği Fakültesi \\ Protetik Diş Tedavisi Anabilim Dalı/DİYARBAKIR \\ Tel: 0412-2488101 -05338127682 \\ Fax: 0412-2488100 \\ Email: mrvokgoz@gmail.com
}

